\title{
Minimal Access Surgery for Cancer Treatment
}

\author{
P.M. Schlag M. Hünerbein \\ Klinik für Chirurgie und Chirurgische Onkologie, Robert-Rössle-Klinik, Universitätsklinikum Charité im HELIOS-Klinikum Berlin
}

Since laparoscopy was first introduced as a diagnostic method for evaluation of pelvic pathology, this technique has been successfully adopted by visceral surgeons as a therapeutic procedure for various intraabdominal diseases. Laparoscopic surgery appears to be an attractive alternative to conventional surgery, mainly because it holds promise to reduce the surgical trauma to the patients. Potential benefits of the laparoscopic approach include less perioperative morbidity, shorter hospital stay, more rapid return to work, and better cosmetics. Following the rapid acceptance of laparoscopic cholecystectomy, various other minimally invasive procedures such as appendectomy, fundoplication, hernia repair and splenectomy have been developed for the treatment of benign diseases. However, despite the apparently overwhelming advantages of laparoscopic surgery, only laparoscopic cholecystectomy and laparoscopic fundoplication have replaced conventional operations as standard techniques. This situation is mainly caused by the considerable operative skills and the long learning curve required for more complex operations. Not at least because of the high costs of laparoscopic instruments the general acceptance of minimal access surgery was limited.

During the last years laparoscopic surgery has also been increasingly applied to malignant diseases. There is increased sensitivity of laparoscopy, with laparoscopic ultrasound as a staging modality in the diagnosis of previously unrecognized metastatic disease from cancer, which is clearly one of the most important applications of laparoscopic technology in this patient population. There is no doubt that diagnostic laparoscopy improves the preoperative staging of intraabdominal tumor spread and may therefore result in more effective treatment of gastrointestinal cancer. It has been shown in numerous studies that staging laparoscopy is more sensitive than preoperative imaging for small-volume tumor deposits such as peritoneal seeding and liver metastases with a diameter of less than $1 \mathrm{~cm}$. Several authors have quoted rates of $20-30 \%$ newly diagnosed metastases by staging laparoscopy despite a thorough preoperative workup of the patients [1-3]. It has been reported that laparoscopic ultrasonography can further increase the accuracy of staging laparoscopy, because it helps to compensate the very limited tactile input with laparoscopic instruments [4].

In contrast to the positive attitude to diagnostic laparoscopy, there has been much debate on whether laparoscopic surgery is appropriate for the management of potentially curable cancer. In the meantime, most experience has been gained with laparoscopic colectomy for colorectal cancer. There is evidence from published series that laparoscopic colectomy for cancer can be performed safely by experienced surgeons, but there is a considerable learning curve for the procedure. According to the literature data, laparoscopic colorectal surgery offers several advantages similar to other laparoscopic procedures [5]. Patients lose less blood, show less immunosuppression, have shorter postoperative ileus, and require less analgesia. Furthermore, the rate of postoperative wound infections seems to be somewhat lower than after conventional resection (1-9\% vs. $4-16 \%$ ). The rate of anastomotic leakage of both techniques is comparable. Minimal access surgery enables to reduce the hospital stay of the patients by approximately $2-5$ days ( $4-8$ days vs. $8-15$ days).

In the meantime it has also been proven that laparoscopic colectomy can be performed without compromising oncologic principles of cancer surgery, i.e., margins of resection and lymph node harvest. No significant differences in the number of resected lymph nodes and in the length of resected bowel have been found between laparoscopic and open colectomies [6,7]. Although surgeons have shown that equivalent resections can be performed, it is not clear yet whether this results in equivalent recurrence and survival rates. Short-term results of both retrospective and prospective trials comparing open with laparoscopic surgery for colorectal cancer suggest comparable oncologic outcomes [6, 8]. However, long-term results are not yet available to assess changes in overall survival and recurrence rates with the laparoscopic technique.

\begin{tabular}{ll}
\hline KARGER & $\odot$ 2002 S. Karger GmbH, Freiburg \\
Fax +497614520714 & Accessible online at: \\
$\begin{array}{l}\text { E-mail Information@Karger.de } \\
\text { www.karger.com }\end{array}$ & www.karger.com/journals/onk
\end{tabular}


Much controversy regarding the use of laparoscopic techniques for colorectal cancer originated from anecdotal reports on port site metastases after partial colectomy. Initial reports from several small series have suggested a rate of $10-20 \%$ port site metastases [10]. Despite extensive research efforts, neither the true incidence of port site recurrence nor its causes have been clarified definitely. Laparoscopic cancer surgery must be considered cautiously until the mechanisms of port site spread are understood and the risk can be prevented. More recent data from larger patient populations indicate a considerably lower risk of port site recurrence (approximately $2 \%$ ) [9]. Preliminary results of recently published studies suggest that port site metastases may not be an inherent problem of laparoscopic surgery, but rather a problem of the complexity of the procedure and the learning curve of laparoscopic surgery in colorectal cancer.

Experimental research and clinical data confirm that laparoscopic cancer surgery is technically feasible. However, laparoscopic surgery for cure of cancer remains investigational and should be limited to clinical trials. Concern still exists regarding the development of port site metastases, the longer operating times, and the overall cost of the equipment. Reliable assessment of these procedures for tumor surgery is still impossible due to the lack of long-term results, the selective experience, and the ongoing process of learning and development. As long-term results of prospective randomized trials are still missing, the crucial issue whether laparoscopic resections are oncologically equivalent to open surgery cannot be answered definitely. However, it seems clear that minimally invasive procedures will play an important role in surgical oncology. This is especially true with respect to improved staging of gastrointestinal tumors by laparoscopy and various palliative procedures that can be performed laparoscopically. Minimally invasive procedures may become a valuable alternative to open surgery in the treatment of selected cases of preneoplastic and early cancerous lesions. The definitive acceptance of minimally invasive procedures in the future necessitates further clinical, preferably randomized trials, comparing the benefits of the minimally invasive access route to possible long-term hazards with regard to recurrence-free and overall survival.

\section{References}

1 Feussner H, Omote K, Fink U, Walker SJ, Siewert JR: Pretherapeutic laparoscopic staging in advanced gastric carcinoma. Endoscopy 1999;31:342347.

2 Hünerbein M, Rau B, Hohenberger P, Schlag PM: The role of staging laparoscopy for multimodal therapy of gastointestinal cancer. Surg Endosc 1998;12:921-925.

3 Schlag PM, Hünerbein M, Rau B: The importance of staging laparoscopy for staging of gastric cancer. Onkologie 1998;21:486-491.

4 Rau B, Hünerbein M, Schlag PM: Laparoskopie und laparoskopische Endosonographie als Staginguntersuchung bei Tumoren des oberen Gastrointestinaltraktes. Zentralbl Chir 1995;120:346-349.
5 Lacy AM, Garcia-Valdecasas JC, Pique JM, Delgado S, Campo E, Bordas JM, Taura P, Grande L, Fuster J, Pacheco JL, et al: Short-term outcome analysis of a randomized study comparing laparoscopic vs open colectomy for colon cancer. Surg Endosc 1995;9:1101-1105.

6 Milsom JW, Bohm B, Hammerhofer KA, Fazio V, Steiger E, Elson P: A prospective, randomized trial comparing laparoscopic versus conventional techniques in colorectal cancer surgery: A preliminary report. J Am Coll Surg 1998;187:46-54.

7 Schwandner O, Schiedeck TH, Killaitis C, Bruch HP: A case-control-study comparing laparoscopic versus open surgery for rectosigmoidal and rectal cancer. Int J Colorectal Dis 1999;14:158-163.
8 Fleshman JW, Wexner SD, Anvari M, LaTulippe JF, Birnbaum EH, Kodner IJ, Read TE, Nogueras JJ, Weiss EG: Laparoscopic vs. open abdominoperineal resection for cancer. Dis Colon Rectum 1999; 42:930-939.

9 Paolucci V, Schaeff B, Schneider M, Gutt C: Tumor seeding following laparoscopy: International survey. World J Surg 1999;23:989-995.

10 Wexner SD, Cohen SM: Port site metastases after laparoscopic colorectal surgery for cure of malignancy. Br J Surg 1995;82:295-298. 